\title{
CLIMATE CHANGE AND UNCERTAINTY
}

\section{Politics and perspectives}

Shilpi Srivastava, Lyla Mehta and Hans Nicolai Adam

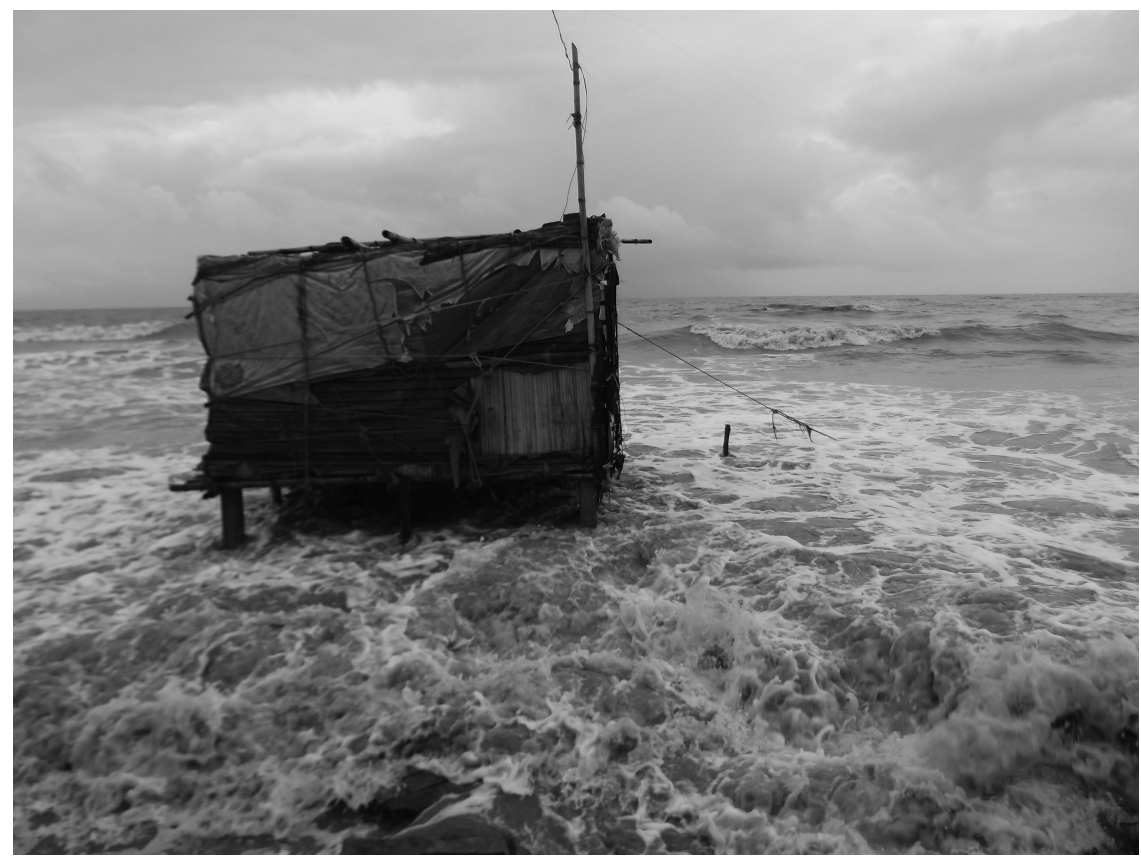

FIGURE 1.1 A dwelling on the verge of being washed away in Ghoramara Island, Sundarbans, India (Photo credit: Shibaji Bose).

\section{Introduction}

Climate change is one of the most critical development challenges of our times. Across the globe, a range of climatic shocks and stressors, often framed as 
"extreme" or "freak events", in the form of floods, droughts, heatwaves and cyclones are intensifying and slowly becoming the new normal (IPCC 2018). Research over the past few decades has demonstrated clearly the links between anthropogenically induced emissions and climate change (IPCC 2014, 2018). Through modelling and analysis, a range of projections for the future have been presented and contested, triggering a new kind of regulatory politics on scenarios and pathways (Beck and Mahony 2017). However, despite these scientific advancements, uncertainties in climate change projections remain particularly high with respect to the scale, intensity and impact of climate change (Curry and Webster 2011). These uncertainties, combined with economic and political drivers of change, make local-level effects difficult to predict (IPCC-SREX 2012) and can also lead to challenges in climate changerelated decision-making (Wilby and Dessai 2010)

Uncertainty is characterised by indeterminacies where not enough is known about the probabilities of a particular set of outcomes and where they cannot be calculated (Knight 1921). Unlike risk, where probabilities of both outcomes and likelihoods are known (Wynne 1992; Stirling 1999), uncertainty is a situation where one does not know the odds and the probabilities cannot be calculated (Scoones and Stirling 2020). Walker et al. (2003: 5) define uncertainty as "any deviation from the unachievable ideal of completely deterministic knowledge of the relevant system" and highlight the importance of understanding the various dimensions of uncertainty for response and action. Within climate change debates, uncertainty is often referred to as a "super wicked problem" or a "monster" (van der Sluijs 2005; Levin et al. 2012) and scientists are increasingly acknowledging that uncertainty is here to stay and it may not be entirely possible to reduce or control (IPCC 2014).

However, there are deep differences in the ways uncertainty is understood, communicated and configured in policy- and decision-making around climate change (see Chapter 2). More fundamentally, significant gaps remain between how uncertainty is dealt within climate science and policy (characterised as the "above" in this volume), how it is experienced by people in their everyday lives (characterised as the "below" in this volume;) and how it is mediated and translated by the "middle" (i.e. the knowledge brokers and intermediaries between the two). These issues are the core focus of the book. Introducing the heuristics of the "above", "middle" and "below", we argue that theorising about climate-related uncertainty by experts, modellers and policymakers may have very little to do with how local people (men, women, third gender who are, in turn, differentiated by age, ableism, class, caste, location and ethnicity) make sense of climate change and live with climate-related uncertainties in everyday settings (see Figure 1.1). We demonstrate in different empirical settings that the reaction from "above" has often been to minimise and control uncertainty and capture it through quantitative assessments and modelling exercises. However, global and regional climate models are less predictable at the local level, especially because climate change often interacts with wider socio-economic drivers of change, 
change, increasing local-level uncertainties. For example, as discussed in Chapter 2, climate change models are associated with a "cascade of uncertainties" that increase with downscaling. These relate to uncertainties in projections, response to changes at global and national scales and the spatial and temporal distribution of impacts, thus creating an "envelope of uncertainty" (Wilby and Dessai 2010). The empirical chapters on Kutch, the Sundarbans and Mumbai demonstrate this cascading view of uncertainty in this volume.

A growing number of authors have discussed key differences between how experts (be they policymakers or scientists) and local people view and experience climate change (e.g. Hastrup and Skrydrstup 2013; Rudiak-Gould 2013; Hulme 2015; Conway et al. 2019). These authors have attempted to validate the placebased knowledge and agency of local expertise vis-à-vis climate and its changes underlining the epistemic contrasts (see García-del-Amo et al. 2020 for Spain; Das 2021 for India). This book builds on this scholarship and demonstrates deep differences in the ways different actors understand and experience climate change and uncertainty. It argues that diverse knowledges and plural approaches need to be deployed to understand and embrace climate-related uncertainties to facilitate transformative and socially just adaptation. The voices and experiences from "below" matter because it is these vulnerable groups living on the frontline and the least responsible for creating climate change - who bear the brunt of anthropogenic climate change. Thus, their knowledges, experiences and responses must inform and feed into wider climate debates and strategies. Our research from India's drylands, wetlands and coast reveals that, neglecting locally relevant and bottom-up perspectives can lead to interventions that exacerbate uncertainties and vulnerabilities of poor and marginalised social groups.

The book demonstrates that it is important to capture a range of perceptions, experiences and responses to climate change and uncertainty (cf. Crate and Nuttall 2009; Jasanoff 2010; Wynne 2010) to appreciate the diverse dimensions of climate and address appropriate strategies regarding both adaptation and mitigation that go beyond short-term incremental impacts and address structural change. For many vulnerable groups at the forefront of climate change, adapting through incremental changes is clearly not sufficient, both because of their limited adaptive capacity and the neglect of wider structural conditions of inequity, powerlessness and marginalisation which can enable maladaptation and intensify structural inequalities and local vulnerabilities (Eriksen et al. 2021). These call for deep-rooted structural transformations (O'Brien 2012).

This volume addresses these challenges and epistemological tensions by examining the concept of uncertainty in relation to climate change from various vantage points of the "above", "middle" and "below", with specific reference to India. It also explores to what extent and how these divides can be bridged so that new hybrid perspectives can facilitate more transformative pathways to adapt to climate change. Our core proposition is that investigating and unpacking the gaps in diverse conceptions of uncertainty can facilitate processes that embrace rather than eliminate uncertainty. This is because subjective judgements, multiple 
knowledges and interpretations around uncertainty tend to be the best way forward instead of a singular value or recommendation (Stirling et al. 2007; Leach et al. 2010; Eriksen et al. 2015; Nightingale et al. 2020). These can ultimately help promote adaptation and mitigation processes that are both socially just and responsive to the socio-ecological diversity of contexts.

\section{Climate change and uncertainty in the Indian context}

India is not only a global hotspot for climate change impacts (Mani et al. 2018) but also has large population sections that are highly vulnerable to the impacts from climate variability and change (IPCC 2014). The causes for this social vulnerability are manifold. The majority of India's population remains dependent on climate-sensitive livelihoods such as agriculture, fisheries, forestry and allied activities. Besides, widespread poverty and growing social, economic and political inequalities in both rural and urban areas adversely affect adaptive capacities of local populations. A recent IPCC report (2018) warns that if global temperatures were to rise beyond $1.5{ }^{\circ} \mathrm{C}$, India faces the prospect of being hit by unprecedented climate extremes and a sharp rise in extreme vulnerabilities of its population by 2050 , with some areas potentially becoming uninhabitable. In 2020, 75\% of districts suffer from climate extremes, with interchanging floods and droughts causing most damages and a spike in such events specifically from 2005 onwards (Mohanty 2020). While extreme events are not new to India (see the historical analysis in Chapter 3), their frequency and severity have increased in recent years. India's pastoralists, farmers and fishers are severely affected because their traditional ways of living and coping with climate uncertainties are being tested as new uncertainties - which we term radical uncertainty - are threatening their livelihoods further (see Chapters 4-6). When new patterns (such as increased frequency or severity of floods) are witnessed in areas that are historically, for the most part, exposed to droughts (e.g. Kutch; Chapter 4), knowledge uncertainties abound as there is little or no prior experience or data to fall back on, giving rise to radical uncertainty. How should India prepare for climate action in the context of this radical uncertainty?

As an emerging economy, India is the third largest contributor to Green House Gases (GHGs) emissions globally, while also having one of the lowest GHG emissions per capita (Dubash 2019). Development inequalities are, however, not limited to differences between the global North and global South. As a recent study highlights in the Indian context (Lee et al. 2021), vast disparities exist between a growing middle- and upper-middle class and poorer communities in India, ${ }^{1}$ the former having an up to seven times higher carbon footprint than the latter. How India will deal with climate change has consequently profound ramifications for its population and its social, environmental and economic policies as well as global climate action. Hence, it is important that developmentfocused interventions are implicitly intertwined with climate policy and their impacts on the ground (Dubash 2019). 
At the national level, India's key strategy papers on climate change are the National Action Plan on Climate Change (NAPCC) (Government of India 2008), the State Action Plans on Climate Change (SAPCC) and, more recently, the Intended Nationally Determined Contributions (INDCs) (see MOEFCC 2015). These documents acknowledge the impacts of climate change on natural resources and people's livelihoods. As we also found in our research in particular contexts in Gujarat, Maharashtra and West Bengal, the official plans continue to place disproportionate emphasis on mitigation and issues of international equity and redistribution, while questions of adaptation, domestic equity and access to natural resources remain side-lined (Bidwai 2012; Venkatesh 2018). The NAPCC has also been criticised for being ill-suited to the Indian context, doing little to balance climate and development concerns and inter-state differences (Bidwai 2012; Dubash et al. 2018). The SAPCCs have seen poor implementation and limited participation by key stakeholders and practitioners in designing strategies and do not acknowledge variations in the ways climate change will play out across regions (see also Chapters 4-6) and the relative capacities of different states to respond to climate change (Dubash and Jogesh 2014; Kumar and Naik 2019). This is despite the initial and cautious optimism that SAPCCs could be a base for mainstreamed climate concerns into development planning (Dubash and Jogesh 2014).

While officials discuss adaptation and climate-friendly initiatives, often there is insufficient actionable planning and dedicated financial allocation for adaptation. The MGNREGA (the largest rural public works programme in the world) has, for instance, been mainstreamed to include climate adaptation concerns (Adam 2015). However, the "retrofitted" scheme is not tailored for taking on a dedicated climate adaptation role, lacking integration of participatory vulnerability assessments, planning or addressing of structural power imbalances (Eriksen et al. 2021). India's cities have also been found to sorely lack strategic integration of climate risks that are informed by principles of sustainable adaptation (Singh et al. 2021), as we also examine in Chapter 6 for Mumbai. This reflects a national trend wherein adaptation funds remain underutilised or diverted for different purposes (Venkatesh 2018). While India is on track to achieve - or even surpass - its ambitious INDCs, which is a positive signal, questions remain on the fundamental premise of being closely linked to a green economy discourse that is associated with business and market-friendly principles, technological optimism and neglect of issues concerning power inequity, marginalisation and resource distribution (Unmüßig et al. 2012).

Srivastava et al. (Chapter 4) discuss how recent mitigation efforts around renewable energy parks can contribute to spatial injustice by leading to further dispossession of pastoralists in Kutch and elsewhere (also see Yenneti et al. 2016). Similarly, Adam et al. (Chapter 6) argue that prioritising mitigation in state-led discourses on climate change within cities has led to the dominance of marketdriven agendas and business ventures, often in the name of energy efficiency and the green economy (e.g. Government of India 2008; MoEFCC 2015). Overall, 
India's climate policy framework is "fragmented and lacks clarity" (Kumar and Naik 2019: 1), displaying the urgent need for a broad-based, inclusive and dedicated climate action for the next decade and beyond. These tensions and trade-offs in the "above" need careful analysis and unpacking, as these top-down interventions often have dramatic impacts on local livelihoods, people's agency, identity and well-being and, more broadly, on the sustainability of India's development trajectory.

\section{Wider relevance}

This volume advances critical social science scholarship on climate change by addressing these challenges and tensions in a lower-middle-income country. Our focus is on marginal environments in India which, despite being ecologically dynamic and climatically vulnerable, suffer from historical neglect. We focus on an urban environment (Mumbai, Maharashtra), dryland (Kutch, Gujarat) and a deltaic ecosystem (Sundarbans, West Bengal) and also analyse their challenges from a historical perspective. These localities offer ecological contrasts, rural-urban/ peri-urban diversity, varied exposure to different climate shocks and diverse state and official responses to climate change and its associated uncertainties. Drawing on diverse theoretical and conceptual approaches (see below) and methodologies, the book investigates the intersection between local understandings of climate change uncertainty with science, politics, culture, history, livelihoods, ecology and a wider political economy in India.

In the past decade, scholarship on climate change in India has increased significantly, indicating the growing interest and importance of climate change in its wider development politics and practice. Several authors have provided a rich account of the national policymaking context in India, locating it within the broader climate and development politics (Dubash 2012, 2018; Taylor, 2014), or within a particular sector or across sectors (Mahdi 2018; Dubash 2019). Other volumes focus on India's climate diplomacy (Saran and Jones 2016) and impacts of adaptation policy (Chattopadhyaya 2014). This is in addition to the vast literature, journal articles, assessment studies (Government of India 2020) and newspaper articles (online and print) that continue to explore the local manifestation of climate change in different state contexts and methodological advancements involving vulnerability assessments that move beyond single values or indicator-based assessments (Singh et al. 2017; Das 2021). Our book builds on this scholarship but takes climate-related uncertainty as its starting point as it connects the global, national and local scales to locate the diverse politics and practice(s) around uncertainty. Further scholarly and practical contributions are as follows:

First, this volume is a significant contribution to understanding how climaterelated uncertainty is understood, experienced, leveraged, lived and embodied by scientists, policymakers and lay people who are socially differentiated due to gender, class, caste, ethnicity and so on. We respond to Jasanoff's call to 
synchronise scientific framings of climate change with "the mundane rhythms of lived lives and specificities of human experience" (2010: 238). In doing so, we introduce the heuristic of "above" and "below" and the "middle" to examine differences in understandings, discourses and practices around uncertainty and climate change and explore the knowledge politics and socio-economic dynamics that shape and alter responses to uncertainty.

Second, climate-related uncertainty has predominantly been characterised as a challenge or a problem that needs resolution. Despite the opening up of approaches to uncertainty and a greater acceptance of the need to embrace it, official responses to dealing with climate-related uncertainty continue to be predominantly driven by top-down, technical and managerial solutions (Beck and Mahony 2017; Mehta et al. 2019) which, as the book will demonstrate, often falter in the face of complex local realities and can create new vulnerabilities (also see Eriksen et al. 2021). Despite a significant emphasis on integrating local knowledge in climate adaptation and decision-making in recent years, much of the scholarship continues to operate within the domain of climate risk (Conway et al. 2019; Conway and Vincent 2021; Singh et al. 2021). Within Indian scholarship, there is limited engagement with the issue of uncertainty barring the work of climate scientists on hydrological resource assessments and planning (Bhave et al. 2018; Joseph et al. 2018; Singh and AchutaRao 2019). This book is, to our knowledge, the first attempt at providing a collection of rich empirical insights on diverse perceptions and experiences of climate-related uncertainties in an Indian context, bringing together macro, meso and micro perspectives. It also stresses the need to prioritise transformative strategies that seriously take on board the perspectives and interests of vulnerable people who bear the brunt of climate change.

Third, we build on growing calls that focus on the need for decision-making under uncertainty (Dessai et al. 2003). In other words, rather than approaches that look at climate science alone in guiding policy responses, there is now a growing body of work that focuses on bringing together top-down and bottomup climate knowledge and assessments (Conway et al. 2019). In line with these shifts, new concepts and practices such as adaptive management practices have emerged that also embrace uncertainty through scenario planning and social learning (Pahl-Wostl et al. 2007; Brugnach et al. 2008; Totin et al. 2018; Kale and D'Souza 2018), creating a citizen science of climate change (Panda 2016), or through assessing the impacts on decision-making and adaptation behaviours (Singh et al. 2016). However, this approach of bridging has found very little salience in the Indian policy context (see Chapters 2 and 7). Both conceptually and empirically, very limited work exists in this domain in the Indian context (Panda 2016). Various chapters in this volume show how uncertainty is viewed by many actors from the "above" as a form of policy paralysis. We explore these various stereotypes and tropes attached to uncertainty while seeking out positive ways in which uncertainty can open up pathways to transformative change. For example, the practices associated with pastoralism are geared to deal with 
uncertain dynamics in ecologically dynamic spaces such as drylands, but these have tended to be ignored in mainstream policymaking. Chapter 4 explores instead how these can be built on to create potentials for transformative action to deal with growing radical uncertainties associated with climate change in drylands (Figure 1.2).

Fourth, the volume contributes to methodological expansion and innovation through its creative application of different disciplinary approaches and methods to study impacts and experiences of, and responses to, climate change and uncertainty across different temporal and spatial scales. It draws on a wide range of epistemic frames, with chapters authored by an interdisciplinary team of leading researchers from anthropology, sociology, economics, history, political science and the natural sciences. The volume draws on original empirical insights from the Indian Sundarbans, Mumbai and Kutch, based on mixed methods (e.g. ethnographic research, visual methodologies, participatory mapping and hazard ranking, semi-structured interviews, participant observation, and quantitative surveys) informed by empirically rich, multi-disciplinary and longue durée research in three distinct socio-ecological settings. Policy analysis and key informant interviews were used to engage with perspectives from "above", and natural science expertise was used to understand climate change trends over time. The book also draws on expertise from the arts and humanities. For example,

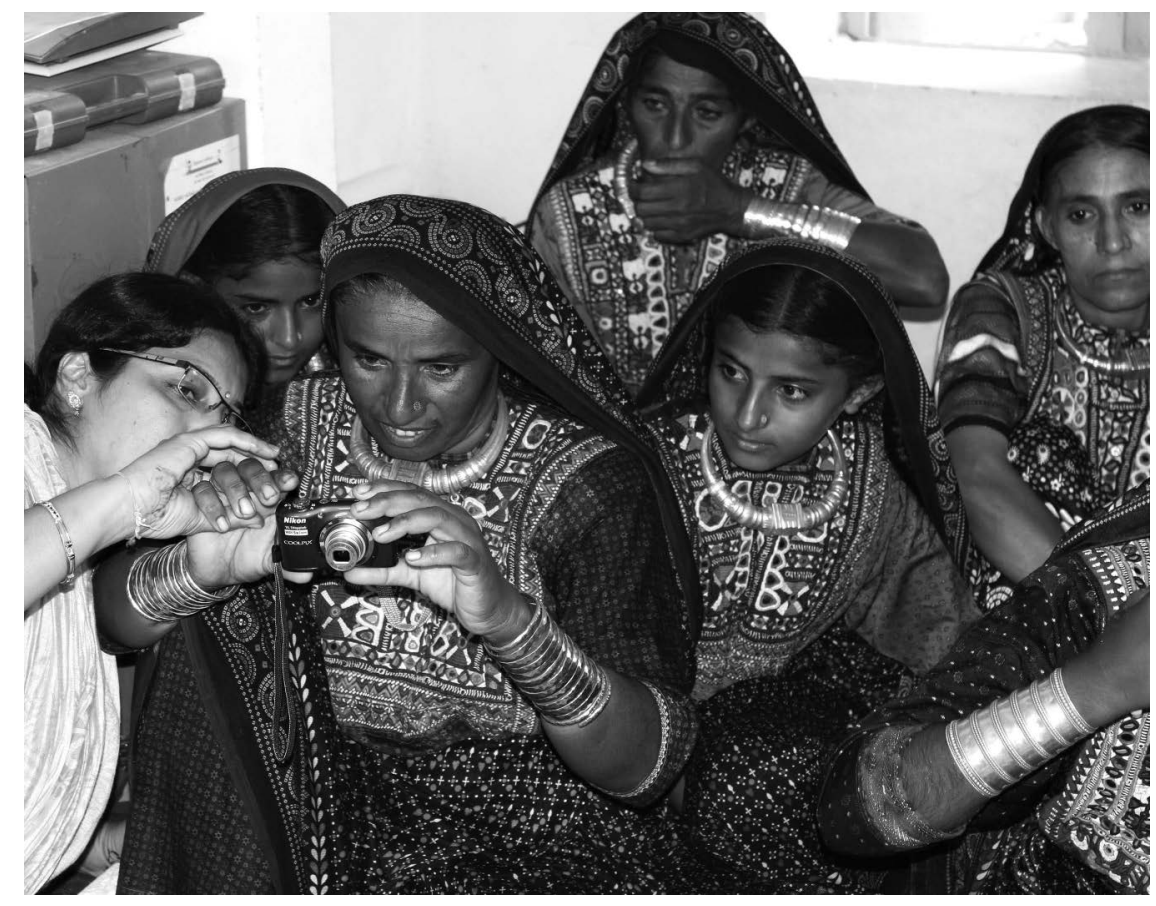

FIGURE 1.2 Photovoice engagement with women in a pastoral community in Kutch (Photo credit: Shibaji Bose). 
Chapter 3 is based on original archival work to analyse colonial understandings of uncertainty in marginal environments, their impacts then and now, and how these inform contemporary climate change debates. In all the research sites, researchers used photovoice to allow hidden and marginalised perspectives to come to the fore through storytelling and visual images. Finally, we also convened roundtables to bridge divides across different disciplinary perspectives and institutional siloes (see Chapters 2 and 7). While unable to get rid of unequal power relations and biases, they at least revealed how these continue to shape and perpetuate dominant paradigms and perspectives.

In the remainder of the introduction, we develop the conceptual framework for this volume, setting the chapters in their context and highlighting the links across various themes.

\section{Heuristics of uncertainty}

As discussed, conceptualisations of uncertainties are varied and are embedded in different realms of knowledge and disciplinary traditions. The largely northern focused literature of Science and Technology Studies (STS) has been critical in elucidating the narrow ways in which uncertainty is often conceptualised by modellers, scientists and planners (e.g. Wynne 1992; Stirling et al. 2007). Other literatures from an anthropological and sociological tradition, and from the perspective of complex ecologies, have demonstrated how local people live with uncertainty and how practices have evolved to deal with it (e.g. Scoones 1994; Vasavi 1999; Adger et al. 2001; Mehta 2005; Marschke and Berkes 2006; Berkes and Berkes 2009). A growing literature in the Indian context and beyond has highlighted the importance of local perceptions about climate variability (Vedwan and Rhoades 2001; Panda 2016; Conway et al. 2019) and resource scarcity (Mehta 2005), and their impact on coping and adaptation behaviours; the importance of local knowledge in adapting to climate change (e.g. Naess 2013); and the wider intersections with local power and social dynamics (Coulthard 2008; Taylor 2014; Adam et al. 2018). While some gaps are being bridged through citizen science of climate change (Panda 2016) and transformative scenario planning (Kale and D'Souza 2018; Totin et al. 2018), largely these different analytical traditions have not spoken to each other. We seek to bridge these literatures through the following heuristics on uncertainty with the caveat that neither of these three categories is homogenous and there is a lot of fluidity across these categories (e.g. scientists can be experts from "above", take on advocacy roles as the "middle" and also experience climate change impacts from "below").

\section{Uncertainty from "above"}

Uncertainty from "above" is represented by climate scientists, policy elites and decision-makers. This is usually linked to powerful agencies, although 
we concede that there will be hierarchies within these and they are not homogeneous categories (Mehta et al. 2019). Uncertainty and climate change from "above" tend to draw on singular rationalities and may seek out singular ways to understand causality (Hulme 2017). At the larger/global scale, the climate is usually seen as abstract and invisible (Rudiak-Gould 2013). The standard approach for conceptualising uncertainty is to quantify it in terms of probabilities (e.g. Sigel et al. 2010) and statistical models that accommodate sophisticated data with multiple variables across a range of spatial and temporal scales. Of course, as Mehta et al. (Chapter 2) show, many modellers acknowledge the limits to models and their predictions due to limited understandings of the climate system and challenges with attribution and downscaling (Shackley and Wynne 1996; Kandlikar et al. 2005; Stainforth et al. 2007; Curry and Webster 2011; Hulme 2013). Moreover, models often become "fluid objects" (Hastrup 2013: 13) where scientific uncertainties are used as a rhetorical device for strategic ends or to negotiate authority in a disputed domain (Campbell 1985).

Representations of uncertainty are not a priori; they are constructed and rationalised through processes. Therefore, different understandings from "above" are linked to particular institutions, positions and contextual factors. As is evident during the COVID-19 pandemic, scientists also struggle with communicating uncertainty effectively to politicians and the public who crave certainty while wanting their research to be policy relevant. For this purpose, boundary ordering devices such as "people [the middle], texts, maps and ideas" play a strong role in science-policy communications as they facilitate the movement of ideas across different social worlds (Star and Griesemer 1989; Shackley and Wynne 1996). Mehta et al. (Chapter 2) explore some of these challenges at the sciencepolicy interface, where uncertainty is often truncated into risks, producing calculative actions and controlling visions that end up closing down possibilities for collaboration, mediation and plural framings. Both Mehta et al. (Chapter 2) and Movik et al. (Chapter 7) discuss the role of bridging devices and hybrid knowledges in bringing the perspectives of the "above" and "below" together, alongside their challenges. Largely, our research has demonstrated that, most often, many of the livelihood practices that intersect with climate change remain unrepresented in the language, representations and imaginaries of the "above", at least in the Indian context. Thus, the narrow frame of uncertainty needs to be broadened and diversified to encompass varieties of uncertainties as understood, experienced and embodied by the "below".

\section{Uncertainty from "below"}

Climate change narratives and perceptions pervade the everyday realities of local people whom we call the "below", especially those who live at the interface of climate stressors, risks and shocks. These constitute people living in the squatter settlements of megacities such as Mumbai, who are exposed to chronic flooding during monsoons or displacements for urban development, or the fisher folks 
in Mumbai, Kutch and the Sundarbans whose livelihoods are threatened due to changes in climate, commercialisation processes and aggressive patterns of industrialisation (Srivastava and Mehta 2017).

A rich body of literature has elucidated how people attach meaning and significance to the world they inhabit and, in turn, gain meanings from the natural world to understand and live with change (cf. Rudiak-Gould 2009; Hastrup and Skydrstrup 2013). Urban studies have also highlighted how uncertainty is an essential dimension of urban life itself and has been a focal theme of those engaged in planning, building and governing cities (Zeiderman et al. 2015). Thus, many indigenous knowledge (IK) systems evolve through adaptive learning based on developing a complex knowledge base of the environment and lessons from past mistakes - a version of "post-normal" science (cf. Funtowicz and Ravetz 1993). While the repertoire of local people is rich and diverse concerning ecological uncertainties which are also experienced in cultural terms (e.g. Bon Bibi in the Sundarbans; Chapter 5), this is also being challenged in multiple ways as we show in the subsequent chapters.

As discussed, climate change and its intersection with other drivers of change present a radical uncertainty that can push local people to the limits of coping or trigger maladaptation. This can lead to a sense of powerlessness for those whose lives and survival are at the frontline of climate change and uncertainty (Hulme, personal communication, 2014) and trigger distress diversification, as we show in the empirical chapters. For example, in all three sites, marginalised people are confronted with climate-related uncertainties and the threat of displacement (Mumbai and the Sundarbans), difficulties in sustaining livelihoods (Kutch, Mumbai and the Sundarbans) and the impacts of neoliberal and unequal growth patterns. In urban Mumbai (Chapter 6), poor people living in flood-prone areas, whose lives and livelihoods are entrenched in informality, lack rights to housing and basic services. This has increased their vulnerability to climatic events. At the same time, they are blamed as "encroachers" that cause flood-related uncertainties for the city in the first place. In Kutch (Chapter 4), pastoralists need to deal with changes in rainfall and a declining grass cover alongside hostile government policies and rapid industrialisation that is leading to dispossession from the commons. Thus, for the "below" in Kutch, Mumbai and the Sundarbans, climate change as a cause for change is often used to signify concerns around shifts in their cultural, physical, social and economic worlds (cf. Hulme 2017). The climate signals are not abstract and distanced but deeply embedded with their livelihoods, migration, mobility and everyday decision-making.

Thus, uncertainty from "below" concerns the framings of lay and local people as differentiated by gender, age, sexuality, class, ethnicity, race and caste. It is "experiential", non-official knowledge, not necessarily played out at the verbal or articulated level but instead is a more "practical" or tacit form of knowledge (cf. Bourdieu 1977). While our concern is largely with marginalised groups and perspectives, this can also be a very heterogeneous group consisting of both rich and poor, powerful and powerless people (Mehta et al. 2019). 
There are, of course, gendered dimensions of climate change and uncertainty as experienced by the "below" and these are highlighted across various chapters. For example, in the Sundarbans (Chapter 5), the growing precarity and livelihood insecurity, due to the loss of land because of erosion and sealevel rise, have led to women needing to move to less profitable, more fragile, risky and marginal activities such as crab catching. This is risky and physically stressful. While both men and women are affected, the intensity is felt more by female-headed households, not least due to massive male out-migration. Also, for many women who are responsible for the health and sustenance of their families, climate change is not something in the future but very much experienced in the here and now, in terms of the impacts of extreme events and stressors on access to safe drinking water, fodder for their animals, availability of fish in the sea and so on. Chapter 4 also elucidates, through the photovoice engagement, many of these gendered, socially and culturally embedded experiences of uncertainty, which are revealed through the powerful images of the "invisible" care economy in Kutch.

\section{Uncertainty and the "middle"}

While there are clear power differentials between "above" and "below", with the "above" tending to be more powerful, we contend that there is potential for collaboration and bridging, usually facilitated by what we have called the actors and spaces in the "middle". The "middle" often plays a critical role in bridging gaps between "place-based" experiences and expertise on climate change and the most detached expert assessments and solutions (cf. Rudiak-Gould 2013; see Chapter 7).

The "middle" is not a scalar category, but a functional one (Srivastava, unpublished). It is constituted by actors who attempt to facilitate convergence across diverse interests through mediation and brokerage. However, they can also use their agency to block particular pathways of change or maintain the status quo. In this vein, it is important to identify these boundary actors and unpack their politics of bridging (Chapter 7). Across various chapters, the "middle" is constituted through its functional attributes, and it is embedded in diverse formal and informal networks (as civil society actors, politicians, street-level bureaucrats) and engages in practices of policy translation, mediation, alliancebuilding and gatekeeping, thereby blocking, shaping and encouraging processes of change (Srivastava, unpublished). As intermediaries, they bridge or create epistemic and institutional divides across the "above" and "below" and facilitate or hinder transformative pathways (cf. Stein et al. 2018). Most often, the "middle" struggles to translate messages from "below" to the "above" (see Chapter 4). But it can also play a key role in reframing and shifting dominant discourses, for example, around the so-called unproductive nature of the drylands in Kutch (see Chapter 4). At times, actors in the "middle" can resort to politicising uncertainty for their own ends (see Chapter 5). The "middle" thus performs a variety of 
functions including translation, bridging and co-production, the latter being significantly crucial for facilitating small but emerging alternatives to deal with uncertainties that can enable locally led and appropriate adaptation processes.

In response to possible caveats from careful readers, we acknowledge that climate change and uncertainty from "above", "middle" and "below" have different relative strengths, epistemological entry points and potential for complementarity (Berkes and Berkes 2009; Mehta et al. 2019), and some actors operate across all three levels. For example, a scientist can be an expert representing the "above", try to mediate between local communities and the state as the "middle" and also experience the changing rhythms of climate change as the "below".

\section{Dimensions of uncertainty}

In this book, we focus on three types of uncertainties: (1) aleatoric or ecological uncertainties, namely, ecological systems characterised by a high degree of variability and disequilibrium dynamics, thus having unknown effects; (2) knowledge or epistemic uncertainties, which refer to indeterminate knowledge about changes and their impacts; and (3) uncertainties linked to larger political economy conditions, which are unanticipated outcomes due to socio-political interventions and intersections and how they are experienced by diverse groups (Wynne 1992; Mehta et al. 1999; Walker et al. 2003; Mehta et al. 2019). All these uncertainties are experienced, framed and interpreted differently by diverse actors and are linked to relations of power that justify different institutional practices and responses (Rein and Schön 1993; Mehta et al. 2019). Historical understandings of both macro- and micro-level changes are also critical to conceptualising and experiencing uncertainty (see Chapter 3). Uncertainty can also be politicised and manipulated by powerful actors or used as an excuse to do nothing (Mehta et al. 1999; Dessai and van der Sluijs 2007). Configurations and experiences of uncertainty are also affected by location-specific contexts. For example, urban residents and institutions in Mumbai may experience and relate to weatherrelated uncertainties in a different way compared to rural and natural resourcedependent communities (Kutch or the Sundarbans), where extreme variability has a direct impact on their resource access and livelihoods. We now focus in detail on these three dimensions which we discuss below.

\section{Aleatoric uncertainty}

The ontological roots of uncertainty lie in several disciplines. These perspectives recognise the inherent variability of a system, for example, Heisenberg's Uncertainty Principle (Heisenberg 1958), which states that there is a limit to what we can know about any given particle at any given point in time. The fact that there is ontological uncertainty in physics is sufficient for a scientist to conclude that uncertainty is a real phenomenon and not just a deficiency in our ability to observe or know, that is, epistemological uncertainty (see below). In relation to ecological 
systems, uncertainty refers to the unpredictable, variable and volatile nature of the natural systems in which humans interact (Mehta et al. 1999). Ecological systems are dynamic, non-equilibrium systems that are characterised by a high degree of variability and volatility (e.g. in the case of extreme weather events). Chaos, randomness and stochastic processes are the order of the day (Scoones 2004). Modellers and climate scientists refer to this as aleatory uncertainty - the natural fluctuations, a high degree of variability and disequilibrium dynamics having unknown effects (AchutaRao 2016; see Chapter 2). All three sites discussed in this book are highly dynamic and uncertainty is writ large in their landscapes. For example, ecological uncertainty is manifested in the ever-changing rhythms of the river that gobbles up and creates new islands in the Sundarbans; the erratic rainfall in Kutch; and the impacts of extreme rainfall events, sea-level rise and flooding on marginal, low-lying lands in Mumbai.

However, often such endemic uncertainties get framed as risks rather than being acknowledged as a fundamental property of the system. Damodaran et al. (Chapter 3) map this friction by analysing the colonial interventions in marginal environments of Kutch and the Sundarbans. They argue that owing to the stabilising and normalising instinct pursued by the rulers, these environments were often framed as environmental extremes which needed to be normalised and tamed. For instance, in Kutch, the colonial administration linked migration not to pastoral rhythms and coping strategies but exclusively to rainfall deficit and weather uncertainty. Well irrigation, consequently, became the widely accepted official response.

\section{Knowledge politics and uncertainty}

A post-structural understanding of knowledge is essentially grounded in the belief that knowledge is socially constructed and inherently plural and partial (Haraway 1988). Thus, different actors frame uncertainty differently, and this is primarily guided by the knowledge systems in which they are embedded and these, in turn, result in knowledge-based uncertainties. This may be due to different interpretations and different normative judgements about a certain event or a long-drawn-out process spread across a particular time scale (Weick 1995; Klinke and Renn 2002). For example, flooding can be viewed as a climate event or a failure of governance in Mumbai (Chapter 6) and villagers have diverse interpretations of the cyclical nature of droughts in Kutch (Chapter 4). These interpretations can be shaped by certain assumptions, value judgements about particular resources (e.g. the coastline as a resource frontier for estate and industrial development in Kutch and Mumbai vs. a rich ecosystem sustaining livelihoods), biases and political commitments as in the sedentary bias associated with pastoralism (see Chapter 4).

These framings highlight how climate realities and futures are socially and politically constructed by different social groups, communities and institutions, and how these constructions often get fed into specific types of - and often 
contrasting - responses. Thus, framing uncertainty as a "monster" would entail a different set of responses (e.g. taming, controlling and reducing it through better scientific modelling; see Chapter 2) as opposed to framings that call for "living with uncertainty" and should lead to policies and programmes which are more locally grounded with possible socially just outcomes. For example, when policymakers in Gujarat often refer to "reducing" uncertainty, they are largely referring to the gaps in information, that is, epistemological uncertainty (Chapter 4). However, as we show, these notions are also mediated by certain knowledge frames and institutional dynamics that eventually shape responses to climate-induced uncertainty.

Several chapters in this book highlight this contrast in different sites and spaces. For example, Mehta et al. (Chapter 2) and Movik et al. (Chapter 7) highlight this divergence at the interface of science and policy, while the ethnographic insights from Srivastava et al. on Kutch (Chapter 4), Ghosh, Kjosavik and Bose on the Sundarbans (Chapter 5) and Adam et al. on Mumbai (Chapter 6) show how these binaries get fed into institutional responses that are too often short-sighted, reactive and anti-poor, as well as antithetical to inherent variability intrinsic to these environments. For example, in Mumbai, the building of structural defence mechanisms and concretisation efforts against flooding are a display of this partial approach to addressing complex environmental concerns and uncertainties, with the result that flooding proliferates and often worsens the situation (Chapter 6). A similar techno-centric approach is driving the embankment politics in the Sundarbans (Chapter 5).

However, uncertainties are not only about the absence of knowledge; they also have diverse material and embodied manifestations often articulated through cognitive, emotive and behavioural reactions (Scoones and Stirling 2020). In this sense, uncertainty is irreducible; something active, present and modulated through actors' "sense of confidence and control" (Penrod 2007: 664). Actors attach meanings to certain events, create plots (Hastrup 2013) and conviction narratives (Tuckett and Nikolic 2017) to make sense of uncertainty, and devise a future course of action.

Several studies have documented how communities who are highly exposed to climate variability adapt to uncertainty (Scoones 1994; Mehta 2005; RudiakGould 2009; Hastrup 2013). In Kutch, for example, local communities have conventionally been equipped to deal with drought-related uncertainties and have adopted diverse strategies to cope and live with water scarcity (Mehta 2005). This is also linked to the practices of anticipation (Hastrup 2013), whereby people attempt to predict, forecast and prepare for both immediate and distant futures drawing on local cosmologies and indigenous traditions. However, the increasingly radical nature of uncertainties is creating manifold challenges for these IK systems.

Although policymakers and scientists tend to concede that more accurate information may help "tame" the radical nature of these uncertainties, the confounding factor of scale remains a challenge because the socio-political 
unknowns of climate change are massive and these often intersect with other "uncertain" drivers of change that compound or cascade into existing problems related to environmental conditions, such as water quality, health, and food and energy security (Chapter 2; also see Conway et al. 2019). This has also led many scholars to recognise that climate is much more than a mere "scientific" fact; it is a combination of social and natural processes (Hastrup 2013). Thus, the prevailing scientific knowledge needs to be understood as a convergence of broader processes, coalitions, motivations, meanings, social and ethical framings, rather than just a natural scientific framing (Shackley and Wynne 1996).

As demonstrated in Chapter 2, there is now a growing acknowledgement that climate science is better at dealing with uncertainties arising due to macro trends such as temperature extremes and sea-level rise than understanding effects at the local level due to downscaling challenges and intersections with other drivers of change (Bhave et al. 2016; see Chapter 2). These include impacts of land use change, water management trends and socio-political and economic processes, which can increase uncertainties for local people (see Swart et al., 2009). These can be described as the "envelope of uncertainty" (Wilby and Dessai 2010) that intersects with social, political, economic, cultural and scientific drivers that are multi-scalar in nature (Gajjar et al. 2018). These drivers also limit the adaptive capacity and pathways to address climate-induced uncertainties (Tschakert 2007; Solecki et al. 2017). It is for these reasons that the abstraction of climate as an objective and a distanced phenomenon has been criticised and the need for more nuanced approaches underlined. It is critical to unpack the understandings of what counts as climate change, how it is known and unevenly experienced, and how power and political economy mediate these interactions (Eriksen et al. 2015; Nightingale 2016; Watts et al. 2017).

\section{The political economy of uncertainty}

As much as uncertainty is natural to a system, it is also created and sustained as the human, ecological and socio-political systems interact in discreet ways. Uncertainties have differential impacts on local people because these are mediated and experienced differently by axes of difference arising due to gender, ethnicity and class, thus exacerbating the vulnerabilities of ordinary people (Adger 1999; Tschakert 2007; Lemos et al. 2016).

In many ways, and to paraphrase Wynne (1992), climate change may not be as apocalyptic as it is made out to be in the models, or, for some, the "apocalypse" (caused by other political, social or economic factors and exacerbated by climate change) has already happened or they have learned to cope or adapt to these changes. These may be a product of intersectional differences arising due to gender, sexuality, age, ableism, caste, class or race, historical or political arrangements such as citizenship, insecure land tenures as well as ownership and access to natural resources. Thus, climate change responses and impacts at the local level are often mediated through holistic experiences of wider ecologies concerning 
land, water and forests, markets and the economy and institutions and governance across scales (Puri 2015). For example, Damodaran et al. (Chapter 3) show how colonial interventions and imaginaries of the environmental "normal" were experienced and discussed differently by layers of society, communities, experts and government officials across the colonial and early post-colonial periods.

Various chapters across the volume explore the diverse range of institutions, processes and structures (climate-related and otherwise) which influence and are shaped by ecological uncertainties such as floods, droughts, cyclones, rainfall variability and extreme weather events. In all three sites, dominant pathways to deal with uncertainty and climate change range between capitalist and growthdriven trajectories (Mumbai and Kutch) to apathy and neglect of the vulnerabilities of poor people (the Sundarbans). To understand these intersections, we build on Douglass and Miller's (2018) conception of compounded disasters, looking at how spatial and/or temporal proximity of ecological, epistemic and political economy uncertainty can have compounding and cascading effects. For example, in the Sundarbans (Chapter 5), slow stressors such as salinity intrusion and coastline erosion gradually erode livelihood resources, culminating in varying forms of distress diversification and leading to compounded uncertainties. This, as we elaborate in various chapters, is a diversification towards less profitable, more precarious and more marginal livelihood activities.

Most of the research was concluded in 2018, but, wherever possible, we have tried to update our findings in light of the COVID-19 pandemic. In all three sites, existing climate uncertainties are compounded as they intersected with the COVID-19 pandemic. For example, cyclones Amphan and Yash which struck in May 2020 and 2021 destroyed agricultural lands and shelter, and severely increased the vulnerabilities of the islanders who were struggling simultaneously from the fallout of COVID-19-related measures. Between March and May 2020, in particular, the pandemic-induced lockdown phases contributed to reverse migration, reduced remittances, food insecurity and livelihood loss by limiting trade and reducing employment opportunities across sites.

\section{Bridging perspectives: towards transformative politics and pathways}

Various chapters of the book demonstrate how uncertainty has created a form of anxiety and alarm for various actors across scales, thus shaping social and political responses. Through different examples of colonial interventions (Chapter 3), or present policy discourses around pastoralism (Kutch), flood governance (Mumbai) or embankment politics (the Sundarbans), various chapters demonstrate that an excessive focus on techno-managerial solutions has provided only limited solutions in addressing uncertainties in these marginal environments. Usually, the perspectives from the "above" and their solutions prevail and governments have largely tended to ignore the more place-based experiences and assessments and the more critical voices from the "middle". 
In Chapter 7, Movik et al. demonstrate how stakeholder dialogues and roundtables were organised as an attempt to break down disciplinary and other divides and bring diverse actors together (also see Bhatt et al. 2018). However, these bridging spaces are also not power neutral and the power imbalances between and across the "above", "middle" and "below" are critical. Methodologically, roundtables became an effective way of understanding the discursive, material and institutional configurations that shape the understanding and response to uncertainty. Thus, a sustained effort is required in bringing to the fore hidden and alternative perspectives, plural ways of valuation and epistemic diversity to foster transformative, socially just and inclusive development.

What does transformative change look like and what practices, politics and knowledges are required? While there are many diverging views of what constitutes transformation, a general consensus is that it goes beyond marginal or incremental change, is non-linear and challenges the status quo of existing development structures and paradigms (Pelling 2011; O’Brien 2012; Mehta et al. 2021). How are these changes enacted or facilitated? Scoones et al. (2020) refer to three approaches to understanding transformation: structural (fundamental ways in which production and consumption are organised and governed), systemic (intentional change to steer complex systems towards normative goals) and enabling approaches (fostering values of agency, justice and capabilities), and emphasise that embracing enabling approaches is key to transformative change.

Building on the notion of systemic change, in this volume, we attempt to seek out bottom-up pathways of transformation in marginal environments that are characterised by radical uncertainty. Although unequal structural conditions shape people's perception, experience and response to climatic uncertainty locking them into maladaptive pathways or distress diversification (Chapters 4-6), we also observe inspiring initiatives that are seeking to challenge incumbent knowledge systems and power relations. In this regard, we follow Few et al. (2017) in underlining transformation as initiatives and practices that go beyond incremental changes and challenge systemic inequalities and ultimately resulting in a fundamental reorientation of power relations, governance regimes, value systems and conceptions of well-being (Pelling et al. 2015).

In this vein, various chapters discuss the notion of hybrid knowledge (Chapters 7 and 8) and hybrid alliances from the "above", "middle" and "below" that are emerging to respond to various climate-related uncertainties, by offering alternative pathways that are attempting to bridge perspectives and experiences across the domains. Here, the role of the "middle" as interlocutors is key. For example, in the Sundarbans, collaborative efforts between NGOs and local communities are helping restore deltaic ecology and livelihoods. Similarly, in Kutch, civil society organisations and pastoralists are challenging dominant state paradigms regarding drylands and pastoralism and working towards ensuring livelihoods security while enhancing biodiversity (Mehta and Srivastava 2020; see Chapter 4). 
Although such initiatives provide the scope to reframe nature-society relations, they also involve a delicate power relationship between different stakeholders, thus begging the question of who is imagining what and for whom? Which perspectives remain hidden and why, and what needs to be done to bring them to the fore? More importantly, how can bottom-up practices foster socially just pathways in the face of regressive politics, authoritarianism and shrinking civic spaces? How can opaque institutional practices of incumbent powers concerning the state, business and science be opened up and made accountable to the needs of the poor and marginalised sections? We argue that transformations are by their very nature multiple and contested and are closely associated and shaped by understandings of culture, place, identity and contingent conditions within the political economy (Brown and Westaway 2011; Scoones et al. 2015). For example, while local communities are affected by the here and now, transformation is usually associated with changing wider systems that are historically enmeshed in unequal power relations, landscape imaginaries and ecological changes (Mehta et al. 2021). Thus, what counts as transformation is not straightforward. It involves critical questions about scale, attribution, temporality, accountability, responsibility and ethics.

In this book, we highlight some of these tensions and dilemmas as the "above", "middle" and "below" shape and respond to different dimensions of climaterelated uncertainties in diverse settings in India. We also offer emerging evidence on bridging these divides, while being alert to the structural drivers of power and inequity. Ultimately such bridging efforts will help facilitate more plural, inclusive and decentralised ways of understanding, embracing and living with uncertainty that can potentially open up pathways for socially just transformative engagement and politics around climate change.

\section{Note}

1 Living on $\$ 1.9$ consumption a day (Lee et al. 2021).

\section{References}

Achutarao, K. 2016. 'Uncertainty from Above: Can It Be Reduced?'. Paper presented at the STEPS Centre Workshop: Climate Change and Uncertainty from Above and Below, New Delhi, 27-28 January.

Adam, H.N. 2015. 'Mainstreaming Adaptation in India-the Mahatma Gandhi National Rural Employment Guarantee Act and Climate Change. Climate and Development, 7.4: 142-152.

Adam, H.N., D.J. Kjosavik, and N. Shanmugaratnam. 2018. 'Adaptation Trajectories and Challenges in the Western Ghats: A Case Study of Attappady, South India'. Journal of Rural Studies, 61: 1-11. doi.org/10.1016/j.jrurstud.2018.05.002

Adger, W.N. 1999. 'Social Vulnerability to Climate Change and Extremes in Coastal Vietnam'. World Development, 27(2): 249-269. doi.org/10.1016/ S0305-750X(98)00136-3 
Adger, W.N., P.M. Kelly, and N. Huu Ninh, eds. 2001. Living with Environmental Change: Social Vulnerability, Adaptation and Resilience in Vietnam. London: Routledge.

Beck, S. and M. Mahony. 2017. 'The IPCC and the Politics of Anticipation'. Nature Climate Change, 7: 311-313. doi.org/10.1038/nclimate3264.

Berkes, F. and M. Berkes. 2009. 'Ecological Complexity, Fuzzy Logic, and Holism in Indigenous Knowledge'. Futures, 41(1): 6-12. https://doi.org/10.1016/j. futures.2008.07.003.

Bhatt, M.R., L. Mehta, S. Bose, H.N. Adam, S. Srivastava, U. Ghosh, S. Movik, N.C. Narayanan, L.O. Naess, D. Parthasarathy, C. Wilson, and V. Pathak. 2018. Bridging the Gaps in Understandings of Uncertainty and Climate Change. Ahmedabad: AIDMI.

Bhave, A.G., D. Conway, S. Dessai, and D.A. Stainforth. 2016. 'Barriers and Opportunities for Robust Decision Making Approaches to Support Climate Change Adaptation in the Developing World'. Climate Risk Management, 14: 1-10. https://doi.org/10.1016/j. crm.2016.09.004

Bhave, A.G., D. Conway, S. Dessai and D.A. Stainforth. 2018. 'Water Resource Planning Under Future Climate and Socioeconomic Uncertainty in the Cauvery River Basin in Karnataka, India'. Water Resources Research, 54(2): 708-728. https://doi. org/10.1002/2017WR020970

Bidwai, P. 2012. The Politics of Climate Change and the Global Crisis: Mortgaging Our Future. New Delhi: Orient Black Swan.

Bourdieu, P. 1977. Outline of a Theory of Practice. Cambridge: Cambridge University Press.

Brown, K. and E. Westaway E. 2011. 'Agency, Capacity, and Resilience to Environmental Change: Lessons from Human Development, Well-being, and Disasters'. Annual Review of Environment and Resources, 36: 321-342. https://doi.org/10.1146/ annurev-environ-052610-092905

Brugnach, M., A. Dewulf, C. Pahl-Wostl, and T. Taillieu. 2008. 'Toward a Relational Concept of Uncertainty: About Knowing Too Little, Knowing Too Differently, and Accepting Not to Know'. Ecology and Society, 13(2): 30.

Campbell, B.L. 1985. 'Uncertainty as Symbolic Action in Disputes Among Experts', Social Studies of Science, 15(3): 429-453.

Chattopadhyay, S. 2014. Climate Change in India: Views on the Concerns of Adaptation and Survival in a Fast Changing World. New Delhi: Iris Publications Ltd.

Conway, D. and K. Vincent. 2021. Climate Risk in Africa: Adaptation and Resilience. Cham: Palgrave Mcmillan.

Conway, D., R.J. Nicholls, S. Brown, M.G.L. Tebboth, W.N. Adger, B. Ahmad, H. Biemans, F. Crick, A.F. Lutz, R.S. De Campos, M. Said, C. Singh, M.A.H. Zaroug, E. Ludi, M. New, and P. Wester. 2019. 'The Need for Bottom-Up Assessments of Climate Risks and Adaptation in Climate-Sensitive Regions'. Nature Climate Change, 9: 503-511. https://doi.org/10.1038/s41558-019-0502-0

Coulthard, S. 2008. 'Adapting to Environmental Change in Artisanal Fisheries - Insights from a South Indian Lagoon'. Global Environmental Change, 18(3): 479-489. https:// doi.org/10.1016/j.gloenvcha.2008.04.003

Crate, S.A. and M. Nuttall. 2009. 'Epilogue: Anthropology, Science, and Climate Change Policy'. In Anthropology and Climate Change: From Encounters to Actions, edited by S.A. Crate and M. Nuttall, 394-400. Walnut Creek, CA: Left Coast Press Inc.

Curry, J.A. and P.J. Webster. 2011. 'Climate Science and the Uncertainty Monster'. Bulletin of the American Meteorological Society, 92(12): 1667-1682. https://doi. org/10.1175/2011BAMS3139.1 
Das, P.V. 2021. 'People's Climate Knowledge Versus Scientists' Climate Knowledge: A Study of Apple Farming Communities in Western Himalayas, India'. GeoJournal. https://doi.org/10.1007/s10708-021-10371-z

Dessai, S. and J. van der Sluijs. 2007. Uncertainty and Climate Change Adaptation: A Scoping Study. Utrecht: Copernicus Institute.

Dessai, S., K. O’Brien, and M. Hulme. 2007. 'Editorial: On Uncertainty and Climate Change'. Global Environmental Change, 17(1): 1-3. https://doi.org/10.1016/j. gloenvcha.2006.12.001

Douglass, M. and M.A. Miller. 2018. 'Disaster Justice in Asia's Urbanising Anthropocene', Environment and Planning E: Nature and Space, 1: 271-287. https://doi. org $/ 10.1177 / 2514848618797333$

Dubash, N.K. 2012. Handbook of Climate Change and India: Development, Politics and Governance. Oxford: Earthscan.

Dubash, N.K., Khosla, R., Kelkar, U. and Lele, S. 2018. India and climate change: Evolving ideas and increasing policy engagement. Annual Review of Environment and Resources, 43: 395-424.

Dubash, N.K. 2019. 'An Introduction to India's Evolving Climate Change Debate'. In India in a Warming World: Integrating Climate Change and Development, edited by N.K. Dubash, 1-28. New Delhi: Oxford University Press.

Dubash, N.K. and A. Jogesh. 2014. 'From Margins to Mainstream? State Climate Change Planning in India'. Economic \& Political Weekly, 49(48): 86-95. https://doi.org/10.1093/ oso/9780199498734.003.0020

Dubash, N.K., R. Khosla, U. Kelkar and S. Lele. 2018. 'India and Climate Change: Evolving Ideas and Increasing Policy Engagement'. Annual Review of Environment and Resources, 43: 395-424. https://doi.org/10.1146/annurev-environ-102017-025809

Eriksen, S., E.L.F. Schipper, M. Scoville-Simonds, K. Vincent, H.N. Adam, N. Brooks, B. Harding, D. Khatri, L. Lenaerts, D. Liverman, M. Mills-Novoa, M. Mosberg, S. Movik, B. Muok, A. Nightingale, H. Ojha, L. Sygna, M. Taylor, C. Vogel, and J.J. West. 2021. 'Adaptation Interventions and their Effect on Vulnerability in Developing Countries: Help, Hindrance or Irrelevance?'. World Development, 141: 105383. https:// doi.org/10.1016/j.worlddev.2020.105383

Eriksen, S.H., A.J. Nightingale, and H. Eakin. 2015. 'Reframing Adaptation: The Political Nature of Climate Change Adaptation'. Global Environmental Change, 35: 523-533. https://doi.org/10.1016/j.gloenvcha.2015.09.014

Few, R., D. Morchain, D. Spear, A. Mensah, and R. Bendapudi. 2017. 'Transformation, Adaptation and Development: Relating Concepts to Practice'. Palgrave Communications, 3: 17092. https://doi.org/10.1057/palcomms.2017.92

Funtowicz, S.O. and J.R. Ravetz. 1993. 'Science for the Post Normal Age'. Futures, 25(7): 739-755. https://doi.org/10.1016/0016-3287(93)90022-L

Gajjar, S.P., C. Singh, and T. Deshpande. 2018. 'Tracing Back to Move Ahead: A Review of Development Pathways that Constrain Adaptation Futures'. Climate and Development, 11(29): 1-15. https://doi.org/10.1080/17565529.2018.1442793

García-del-Amo, D., P.G. Mortyn and V. Reyes-García. 2020. 'Including Indigenous and Local Knowledge in Climate Research: An Assessment of the Opinion of Spanish Climate Change Researchers'. Climatic Change, 160: 67-88. https://doi.org/10.1007/ s10584-019-02628-x

Government of India. 2008. National Action Plan on Climate Change (NAPCC). New Delhi: Prime Minister's Office. 
Government of India. 2020. Assessment of Climate Change Over the Indian Region: A Report of the Ministry of Earth Sciences (MoES), Government of India. Germany: Springer Singapore.

Haraway, D. 1988. 'Situated Knowledges: The Science Question in Feminism and the Privilege of Partial Perspective'. Feminist Studies, 14: 575-599. https://doi. org $/ 10.2307 / 3178066$

Hastrup, K. 2013. 'Anticipating Nature: The Productive Uncertainty of Climate Models'. In The Social Life of Climate Change Models: Anticipating Nature, edited by K. Hastrup and M. Skrydstrup, 1-29. London: Routledge.

Hastrup, K. and M. Skrydstrup. 2013. The Social Life of Climate Change Models: Anticipating Nature. New York: Routledge.

Heisenberg, W., and F.S.C. Northrop. 1958. Physics and Philosophy: The Revolution in Modern Science. New York: Harper \& Brothers.

Hulme, M. 2013. 'How Climate Models Gain and Exercise Authority'. In The Social Life of Climate Change Models: Anticipating Nature, edited by K. Hastrup and M. Skrydstrup, 30-44. London: Routledge.

Hulme, M. 2015. 'Climate and Its Changes: A Cultural Appraisal', Geo: Geography and Environment, 2(1): 1-11. https://dx.doi.org/10.1002/geo2.5

Hulme, M. 2017. Weathered: Cultures of Climate. London: Sage.

IPCC-SREX . 2012. 'Managing the risks of extreme events and disasters to advance climate change adaptation: A Special Report of Working Groups I and II of the Intergovernmental Panel on Climate Change', In edited by C.B. Field., V. Barros, T.F. Stocker, D. Qin, D.J. Dokken, K.L. Ebi, M.D. Mastrandrea, K.J. Mach, G.K. Plattner, S.K. Allen, M. Tignor, and P.M. Midgley, 1-582. Cambridge, United Kingdom and New York: Cambridge University Press and IPCC.

IPCC. 2014. 'Climate Change 2014: Synthesis Report'. Switzerland: IPCC.

IPCC. 2018. 'Summary for Policymakers'. In Global Warming of $1.5^{\circ} \mathrm{C}$. An IPCC Special Report on the Impacts of Global Warming of $1.5^{\circ} \mathrm{C}$ Above Pre-Industrial Levels and Related Global Greenhouse Gas Emission Pathways, in the Context of Strengthening the Global Response to the Threat of Climate Change, Sustainable Development, and Efforts to Eradicate Poverty. Switzerland: IPCC.

Jasanoff, S. 2010. 'A New Climate for Society'. Theory, Culture \& Society, 27(2-3): 233253. https://doi.org/10.1177/0263276409361497

Joseph, J., S. Ghosh, A. Pathak, and A.K. Sahai. 2018. 'Hydrologic Impacts of Climate Change: Comparisons between Hydrological Parameter Uncertainty and Climate Model Uncertainty'. Journal of Hydrology, 566: 1-22. https://doi.org/10.1016/j. jhydrol.2018.08.080

Kale, E. and M. D’Souza. 2018. Using Transformative Scenario Planning to Think Critically About the Future of Water in Rural Jalna, India. Ottawa: International Development Research Centre.

Kandlikar, M., J. Risbey, and S. Dessai. 2005. 'Representing and Communicating Deep Uncertainty in Climate-Change Assessments'. Comptes Rendus Geoscience, 337(4): 443-455. https://doi.org/10.1016/j.crte.2004.10.010

Klinke, A. and O. Renn. 2002. 'A New Approach to Risk Evaluation and Management: Risk-Based, Precaution-Based, and Discourse-Based Strategies'. Risk Analysis, 22(6): 1071-1094. https://doi.org/10.1111/1539-6924.00274

Knight, F.H. 1921. Risk, Uncertainty and Profit. Chicago, IL: Chicago University Press.

Kumar, P. and A. Naik. 2019. 'India's Domestic Climate Policy Is Fragmented and Lacks Clarity', Economic \& Political Weekly, 54(7): 1-13. 
Leach, M., I. Scoones and A. Stirling. 2010. Dynamic Sustainabilities: Technology, Environment, Social Justice. London: Earthscan.

Lee, J., O. Taherzadeh and K. Kanemoto. 2021. 'The Scale and Drivers of Carbon Footprints in Households, Cities and Regions across India'. Global Environmental Change, 66: 102205. https://doi.org/10.1016/j.gloenvcha.2020.102205

Lemos, M.C., Y.-J. Lo, D. Nelson, H. Eakin, and A.M. Barbieri Bedran Martins. 2016. 'Linking Development to Climate Adaptation: Leveraging Generic and Specific Capacities to Reduce Vulnerability to Drought in NE Brazil'. Global Environmental Change, 39: 170-179. https://doi.org/10.1016/j.gloenvcha.2016.05.001

Levin, K., B. Cashore, S. Bernstein, and G. Auld. 2012. 'Overcoming the Tragedy of Super Wicked Problems: Constraining Our Future Selves to Ameliorate Global Climate Change'. Policy Sciences, 45(2): 123-152.

Mahdi, S.S. 2018. Climate Change and Agriculture in India: Impact and Adaptation. New York: Springer International Publishing.

Mani, M., S. Bandyopadhyay, S. Chonabayashi, A. Markandya, and T. Mosier. 2018. South Asia's Hotspots: Impacts of Temperature and Precipitation Changes on Living Standards. Washington, DC: World Bank.

Marschke, M. and F. Berkes. 2006. 'Exploring Strategies that Build Livelihood Resilience: A Case from Cambodia'. Ecology and Society, 11(1): 42.

Mehta, L. 2005. The Politics and Poetics of Water: Naturalising Scarcity in Western India. New Delhi: Orient Longman.

Mehta, L., M. Leach, P. Newell, I. Scoones, K. Sivaramakrishnan, and S.A. Way. 1999. 'Exploring Understandings of Institutions and Uncertainty: New Directions in Natural Resource Management'. IDS Discussion Paper 372. Brighton: IDS.

Mehta, L. and S. Srivastava. 2020. 'Uncertainty in Modelling Climate Change: The Possibilities of Co-production Through Knowledge Pluralism'. In The Politics of Uncertainty: Challenges of Transformation, edited by I. Scoones and A. Stirling, 99-112. London: Routledge.

Mehta, L., S. Srivastava, H.N. Adam, S. Bose, U. Ghosh, and V.V. Kumar. 2019. 'Climate Change and Uncertainty from 'Above' and 'Below': Perspectives from India'. Regional Environmental Change, 19(6): 1533-1547. https://doi.org/10.1007/ s10113-019-01479-7

Mehta, L., S. Srivastava, S. Movik, H.N. Adam, R. D’Souza, D. Parthasarathy, L.O. Naess and N. Ohte. 2021. Transformation as Praxis: Responding to Climate Change Uncertainties in Marginal Environments in South Asia. Current Opinion in Environmental Sustainability, 49, 110-117. https://doi.org/10.1016/j.cosust.2021.04.002

MoEFCC. 2015. India's Intended Nationally Determined Contribution: Working towards Climate Justice. New Delhi: Ministry of Environment, Forest and Climate Change.

Mohanty, A. 2020. Preparing India for Extreme Climate Events: Mapping Hotspots and Response Mechanisms. New Delhi: Council on Energy, Environment and Water.

Naess, L.O. 2013. 'The Role of Local Knowledge in Adaptation to Climate Change'. Wiley Interdisciplinary Reviews: Climate Change, 4(2): 99-106. https://doi.org/10.1002/ wcc. 204

Nightingale, A.J. 2016. 'Adaptive Scholarship and Situated Knowledges? Hybrid Methodologies and Plural Epistemologies in Climate Change Adaptation Research'. Area, 48(1): 41-47. https://doi.org/10.1111/area.12195

Nightingale, A.J., S. Eriksen, M. Taylor, T. Forsyth, M. Pelling, A. Newsham, E. Boyd, K. Brown, B. Harvey, L. Jones, R. Bezner Kerr, L. Mehta, L.O. Naess, D. Ockwell, I. Scoones, T. Tanner, and S. Whitfield. 2020. 'Beyond Technical Fixes: Climate 
Solutions and the Great Derangement'. Climate and Development, 12(4): 343-352. https://doi.org/10.1080/17565529.2019.1624495

O'Brien, K. 2012. 'Global Environmental Change II: From Adaptation to Deliberate Transformation'. Progress in Human Geography, 36: 667-676. https://doi. org $/ 10.1177 / 0309132511425767$

Pahl-Wostl, C., M. Craps, A. Dewulf, E. Mostert, D. Tabara, and T. Taillieu. 2007. 'Social Learning and Water Resources Management'. Ecology and Society, 12(2): 5.

Panda, A. 2016. 'Exploring Climate Change Perceptions, Rainfall Trends and Perceived Barriers to Adaptation in a Drought Affected Region in India'. Natural Hazards, 84(2): 777-796. https://doi.org/10.1007/s11069-016-2456-0

Pelling, M. 2011. Adaptation to Climate Change: From Resilience to Transformation. London: Routledge.

Pelling, M., K. O’Brien, and D. Matyas. 2015. 'Adaptation and Transformation'. Climatic Change, 133: 113-127. https://doi.org/10.1007/s10584-014-1303-0

Penrod, J. 2007. 'Living with Uncertainty: Concept Advancement'. Journal of Advanced Nursing, 57: 658-667. https://doi.org/10.1111/j.1365-2648.2006.04008.x

Puri, R. 2015. 'The Uniqueness of the Everyday: Herders and Invasive Species in India'. In Climate Cultures: Anthropological Perspectives on Climate Change, edited by J. Barnes and M.R. Dove, 249-273. New Haven, CT: Yale University Press.

Rein, M. and D. Schön. 1993. 'Reframing Policy Discourses'. In The Argumentative Turn in Policy Analysis and Planning, edited by F. Fischer and J. Forester, 145-166. Durham, NC: Duke University Press.

Rudiak-Gould, P. 2009. The Fallen Palm: Climate Change and Culture Change in the Marshall Islands. Riga: VDM Verlag Dr. Müller.

Rudiak-Gould, P. 2013. “We Have Seen It with Our Own Eyes”: Why We Disagree about Climate Change Visibility'. Weather, Climate, and Society, 5(2): 120-132.

Saran, S. and A. Jones. 2016. India's Climate Change Identity: Between Reality and Perception. Cham: Palgrave Macmillan.

Scoones, I. 1994. Living With Uncertainty: New Directions in Pastoral Development in Africa. London: Intermediate Technology Publications.

Scoones, I. 2004. 'Climate Change and the Challenge of Non-Equilibrium Thinking', IDS Bulletin, 35: 114-119. https://doi.org/10.19088/1968-2020.116

Scoones, I. and A. Stirling. 2020. 'Uncertainty and the Politics of Transformation'. In The Politics of Uncertainty: Challenges of Transformation, edited by I. Scoones and A. Stirling, 1-30. London: Routledge.

Scoones, I., M. Leach and P. Newell. 2015. The Politics of Green Transformations. London: Routledge.

Scoones I., A. Stirling, D. Abrol, [...] L. Yang. 2020. Transformations to Sustainability: Combining Structural, Systemic and Enabling Approaches. Current Opinion in Environmental Sustainability, 42: 65-75. https://doi.org/10.1016/j.cosust.2019.12.004

Srivastava S. 2018. Action in the 'middle': Mid-level actors, climate change and intersectoral collaboration in urban India: Literature Review (unpublished)

Stirling A., M. Leach, L. Mehta [...] J. Thompson. 2007. Empowering designs: towards more progressive appraisal of sustainability. STEPS Working Paper 3, STEPS Centre, Brighton.

Shackley, S. and B. Wynne. 1996. 'Representing Uncertainty in Global Climate Change Science and Policy: Boundary-Ordering Devices and Authority’. Science, Technology \& Human Values, 21: 275-302. 
Sigel, K., B. Klauer, and C. Pahl-Wostl. 2010. 'Conceptualising Uncertainty in EnvironmentalDecision-Making: The Example of the EU Water Framework Directive'. Ecological Economics, 69: 502-510. https://doi.org/10.1016/j.ecolecon.2009.11.012

Singh, R., \& K. AchutaRao. 2019. Quantifying uncertainty in twenty-first century climate change over India. Climate Dynamics, 52(7): 3905-3928.

Singh, C., M. Madhavan, J. Arvind, and A. Bazaz. 2021. 'Climate Change Adaptation in Indian Cities: A Review of Existing Actions and Spaces for Triple Wins'. Urban Climate, 36: 100783. https://doi.org/10.1016/j.uclim.2021.100783

Singh, C., P. Dorward, and H. Osbahr. 2016. 'Developing a Holistic Approach to the Analysis of Farmer Decision-Making: Implications for Adaptation Policy and Practice in Developing Countries'. Land Use Policy, 59: 329-343. https://doi.org/10.1016/j. landusepol.2016.06.041

Singh, C., T. Deshpande, and R. Basu. 2017. 'How Do Ee Assess Vulnerability to Climate Change in India? A Systematic Review of Literature'. Regional Environmental Change, 17(2): 527-538. https://doi.org/10.1007/s10113-016-1043-y

Solecki, W., M. Pelling, and M. Garschagen. 2017. 'Transitions between Risk Management Regimes in Cities'. Ecology and Society, 22(2): 38. https://doi.org/10.5751/ ES-09102-220238

Srivastava, S. and L. Mehta. 2017. The Social Life of Mangroves: Resource Complexes and Contestations on the Industrial Coastline of Kutch, India. Brighton: ESRC STEPS Centre.

Stainforth, D.A., M.R. Allen, E.R. Tredger, and L.A. Smith. 2007. 'Confidence, Uncertainty and Decision-Support Relevance in Climate Predictions'. Philosophical Transactions of the Royal Society of London A: Mathematical, Physical and Engineering Sciences, 365: 2145-2161. https://doi.org/10.1098/rsta.2007.2074

Star, S.L. and J.R. Griesemer. 1989. 'Institutional Ecology, 'Translations' and Boundary Objects: Amateurs and Professionals in Berkeley's Museum of Vertebrate Zoology, 1907-39'. Social Studies of Science, 19: 387-420. https://doi.org/10.1177 \%2F030631289019003001

Stein, C., C. Pahl-Wostl, and J. Barron. 2018. 'Towards a Relational Understanding of the Water-Energy-Food Nexus: An Analysis of Embeddedness and Governance in the Upper Blue Nile region of Ethiopia'. Environmental Science and Policy, 90: 173-182. https://doi.org/10.1016/j.envsci.2018.01.018

Stirling, A. 1999. 'On "Precautionary" and "Science-Based" Approaches to Risk Assessment and Environmental Appraisal'. In On Science and Precaution in the Management of Technological Risk, edited by A. Klinke, O. Renn, A. Rip, A. Salo and A. Stirling. Brussels: ECSC-EEC-EAEC.

Stirling, A., M. Leach, L. Mehta, I. Scoones, A. Smith, S. Stagl, and J. Thompson. 2007. 'Empowering Designs: Towards More Progressive Appraisal of Sustainability'. STEPS Working Paper 3, Institute of Development Studies, Brighton.

Swart R., L. Bernstein , M. Ha-Duong and J. Petersen. 2009. 'Agreeing to disagree: uncertainty management in assessing climate change, impacts and responses by the IPCC'. Climatic Change, 92: 1-9.

Taylor, M. 2014. The Political Ecology of Climate Change Adaptation: Livelihoods, Agrarian Change and the Conflicts of Development. London: Routledge.

Totin, E., J.R. Butler, A. Sidibé, S. Partey, P.K. Thornton, and R. Tabo. 2018. 'Can Scenario Planning Catalyse Transformational Change? Evaluating a Climate Change Policy Case Study in Mali'. Futures, 96: 44-56. https://doi.org/10.1016/j. futures.2017.11.005 
Tschakert, P. 2007. 'Views from the Vulnerable: Understanding Climatic and Other Stressors in the Sahel'. Global Environmental Change, 17: 381-396. https://doi.org/10. 1016/j.gloenvcha.2006.11.008

Tuckett, D. and M. Nikolic. 2017. 'The Role of Conviction and Narrative in DecisionMaking under Radical Uncertainty'. Theory \& Psychology, 27: 501-523. https://doi. org/10.1177/0959354317713158

Unmüßig, B., W. Sachs and T. Fatheuer. 2012. Critique of the Green Economy: Towards Social and Environmental Equity. Berlin: Heinrich Böll Foundation.

van der Sluijs, J. 2005. 'Uncertainty as a Monster in the Science-Policy Interface: Four Coping Strategies'. Water Science \& Technology, 52: 87-92.

Vasavi, A.R. 1999. Harbingers of Rain: Land and Life in South India. Delhi: Oxford University Press.

Vedwan, N. and R.E. Rhoades. 2001. 'Climate Change in the Western Himalayas of India: A Study of Local Perception and Response'. Climate Research, 19: 109-117.

Venkatesh, S. 2018. 'Union Budget 2018: Climate Action Funds Lying Unused is a Concern'. Down to Earth, New Delhi, 17 January.

Walker, W.E., P. Harremoës, J. Rotmans, J.P. van der Sluijs, M.B.A. van Asselt, P. Janssen, and M.P. Krayer von Kraus. 2003. 'Defining Uncertainty: A Conceptual Basis for Uncertainty Management in Model-Based Decision Support'. Integrated Assessment, 4(1): 5-17. https://doi.org/10.1076/iaij.4.1.5.16466

Watts, N., W.N. Adger, S. Ayeb-Karlsson, Y. Bai, P. Byass, D. Campbell-Lendrum, T. Colbourn, P. Cox, M. Davies, M. Depledge, A. Depoux, P. Dominguez-Salas, P. Drummond, P. Ekins, A. Flahault, D. Grace, H. Graham, A. Haines, I. Hamilton, A. Johnson, I. Kelman, S. Kovats, L. Liang, M. Lott, R. Lowe, Y. Luo, G. Mace, M. Maslin, K. Morrissey, K. Murray, T. Neville, M. Nilsson, T. Oreszczyn, C. Parthemore, D. Pencheon, E. Robinson, S. Schütte, J. Shumake-Guillemot, P. Vineis, P. Wilkinson, N. Wheeler, B. Xu, J. Yang, Y. Yin, C. Yu, P. Gong, H. Montgomery, and A. Costello. 2017. 'The Lancet Countdown: Tracking Progress on Health and Climate Change', The Lancet, 389(10074): 1151-1164. https://doi.org/10.1016/ S0140-6736(16)32124-9

Weick, K.E. 1995. Sensemaking in Organizations. Thousand Oaks, CA: Sage Publications. Wilby, R.L. and S. Dessai. 2010. 'Robust Adaptation to Climate Change'. Weather, 65: 180-185. https://doi.org/10.1002/wea.543

Wynne, B. 1992. 'Uncertainty and Environmental Learning: Reconceiving Science and Policy in the Preventive Paradigm'. Global Environmental Change, 2: 111-127. https:// doi.org/10.1016/0959-3780(92)90017-2

Wynne, B. 2010. 'Strange Weather, Again: Climate Science as Political Art'. Theory, Culture \& Society, 27: 289-305. https://doi.org/10.1177/0263276410361499

Yenneti, K., R. Day and O. Golubchikov. 2016. 'Spatial Justice and the Land Politics of Renewables: Dispossessing Vulnerable Communities through Solar Energy MegaProjects', Geoforum, 76: 90-99. https://doi.org/10.1016/j.geoforum.2016.09.004

Zeiderman, A., S.A. Kaker, J.D. Silver, and A. Wood. 2015. 'Uncertainty and Urban Life', Public Culture, 27: 281-304. http://dx.doi.org/10.1215/08992363-2841868 